\title{
Scale-Up of Solid-Liquid Mixing Based on Constant Power/Volume and Equal Blend Time Using VisiMix Simulation
}

\author{
Megawati ${ }^{1}$, Bayu Triwibowo ${ }^{1}$, Karwono ${ }^{2}$, Waliyuddin Sammadikun ${ }^{1}$ and Rofiatun Musfiroh ${ }^{1}$ \\ ${ }^{1}$ Chemical Engineering Department, Engineering Faculty, Universitas Negeri Semarang, Semarang, Indonesia \\ ${ }^{2}$ Mechanical Engineering Department Engineering Faculty, Universitas Negeri Semarang, Semarang, Indonesia
}

\begin{abstract}
Mixing is one of the important process in many areas of chemical industries, for instance pharmaceutical, drug, ink, paint and other industries. Solid-liquid suspension is produced for $80 \%$ of all mixing industries such as leaching process, crystallization process, catalytic reactions, precipitation, coagulation, dissolution and other applications. Two main objectives in solid-liquid mixing namely, avoid settling of solid particles on the tank bottom and ensure the solid particles are uniformly distributed. Many factors that can affect the quality of solid-liquid mixing, they are tank geometry, impeller geometry and speed, baffles, viscosity and density of media. Scale-up of the process is important to conduct before produce it on commercial scale. Two parameters for scale-up solid-liquid mixing are equal blend time and power per volume. Before scaling up the process to industrial scale, an engineer must know the condition of the mixture between both of two. VisiMix can simulating scale-up of solid-liquid mixing in order to know the phenomena inside the tank without conducting a large number of experiments and cheaper. The simulation start from keep the ratio of impeller to tank diameter remains constant, then change the condition operation of mixing. In this paper, power per volume parameter is more recommended as a result of the degree of uniformity of solid phase in liquid.
\end{abstract}

\section{Introduction}

Mixing in stirred tank is one of important process in many areas of chemical industries, for instance pharmaceutical, drug, food, ink, paint and other industries. Mixing is a dynamic generated by impeller rotation where the difference of pressure in various areas of the stirred tank acts as driving force [1]. The object of mixing is to reduce the heterogeneous properties within the tank and provide a uniform mixture. Also, mixing give a better mass transfer in the shortest possible time [2].

Stirred tank was equipped by one or multi impellers like propeller, paddle, or turbine. The impeller creates a flow circulation and mix the fluid within a stirred tank to cause bulk motion in micro scale. The motion is promoted by transfer energy of the impeller into the process of fluid [3]. The process fluid may be single phase (miscible or immiscible liquid) or multiphase (solid, liquid and gas).

Solid-liquid suspension is produced for $80 \%$ of all mixing industries such as leaching process, crystallization process, catalytic reactions, precipitation, coagulation, dissolution and other applications [4]. There are two main objectives in solid-liquid mixing namely, avoid settling of solid particles on the tank bottom and ensure the solid particles are uniformly distributed. In many operations, it is essential to keep all solids in motion in order to prevent the accumulation of solids on the tank. Another important objective of solid-liquid performance is the distribution of solids throughout the tank. Very often, a uniform dispersion of solids throughout the tank is necessary to ensure adequate exposure to the process conditions. However, quantitative information in this area is limited and mostly are confined to low concentration in small tank [3].

To get two of those objectives, the speed of impeller rotation should be higher than Just Suspension Speed (JSS). JSS is the minimum impeller speed that does not result in settling of solid particles. The higher impeller speed will increase the uniformity of solid phase. Therefore, the suspensions of solid particles in liquid media must be complete in order to meet a requirement set in the industry.

Many factors can affect the quality of solid-liquid mixing, they are tank geometry, impeller geometry and speed, baffles, density and rheological properties of liquid. Those factors are a requirement in designing stirred tank, for example the position of three blades propeller within the liquid is $1 / 3$ of the media level [5].

Scale-up is important to conduct in order to produce a chemical product on commercial scale. A good quality of mixing-based product depends on condition of mixing itself on commercial-scale. The product is tried in labscale then study the performance of mixing process on it. Two parameters for scale-up are mixing time and power. 
These parameters must be close as possible both of these scales by arranging impeller, tank geometry, and operating condition. The condition within a stirred tank can be known by VisiMix Simulation software. This paper will discuss scale-up solid-liquid mixing including axial and radial distribution of solid phase, energy and force, macromixing time and hydrodynamic output. Finally, an engineer can be aware some consideration in order to make mixing-based product on industrial scale.

\section{Theory}

\subsection{Complete suspension}

A suspension is defined as being completed when no particles remain on the tank bottom for more than 1-2 $\mathrm{s}$ [6]. Under this condition the total surface of the solid phase are suspended in the liquid and will cause mass transfer phenomena.

A solid particle is just lifted from the bottom of a stirred tank when the forces exerted on that particle by the turbulent motion of the fluid become equal to apparent weight of that particle where the solid particles size is between $100 \mu \mathrm{m}$ and $2 \mathrm{~mm} \mathrm{[7].} \mathrm{For} \mathrm{normal} \mathrm{mixing}$ operation the latter length scale is $40 \mu \mathrm{m}$ orders and determined by the impeller dimensions. So, it may assume that the size of the eddies which pick up the particles is in the inertial subrange of the turbulence spectrum [8].

\subsection{Just suspension speed}

Just Suspension Speed (JSS) is the minimum impeller speed at which no solid particle remains stationary on the tank bottom for $\leq 1-2$ second and with the accuracy of 2 $3 \%$ [9]. Just suspension speed could be estimated by Zwietering correlation. The correlation based on experiments and its dimensionless number as is expressed in Equation 1.

$$
N_{j s}=s v^{0.1}\left(\frac{g \Delta p}{p l}\right)^{0.45} d_{p}^{0.2} X^{0.13} D^{-0.85}
$$

Where $\mathrm{N}_{\mathrm{js}}$ is just suspension speed, $\mathrm{s}$ is the geometrical constant, $v$ is kinematic viscosity, $g$ is gravity acceleration, $\Delta \mathrm{p}$ is density difference, $p l$ is liquid density, $d_{p}$ is particle size, $X$ is mass ratio of solid to liquid, and $D$ is impeller diameter.

\subsection{Scale-up of solid-liquid mixing}

Equal blend time and power per volume $(\mathrm{P} / \mathrm{V})$ are parameters that frequently used to increase the capacity of mixing-based product. Impeller can operate to mix a mixture system within a stirred tank due to a power. Equal blend time consider the time required to achieve the maximum of the degree uniform mixture. An engineer must clear what the need of mixing process. For instance, equal blend time must be selected if the process is faster [10].

In case where the impeller speed higher than JSS, scale-up should be done on $\mathrm{P} / \mathrm{V}$ criteria. In the other research [11] stated that when similar $\mathrm{P} / \mathrm{V}$ is maintained of two units that geometrically similar, the solid-liquid mass transfer coefficient remains similar.

\subsection{Geometry similarity}

Geometry similarity tank for P/V rules can be used when the density difference between solid and liquid is small [12]. The design of mixing tank both lab-scale and commercial scale are shown in Figure 1. Equation 2 is satisfied for exact geometry similarity [10].

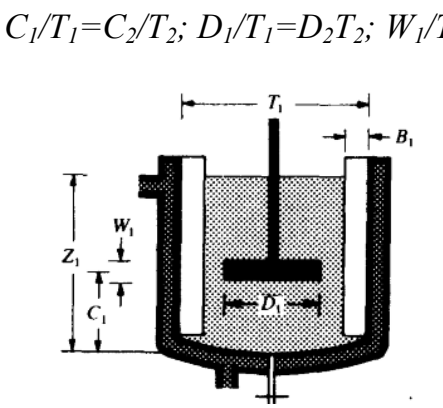

(a)
Figure 1. (a) Lab-scale (b) Commercial-scale.

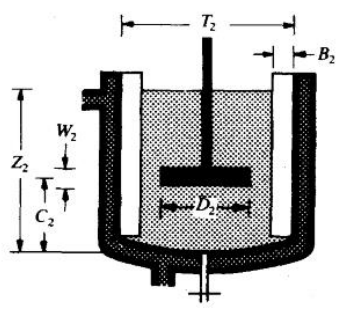

(b)

\subsection{VisiMix simulation}

VisiMix is a simulation application for many mixing processes. The model of simulation based on Kolgomogoroff, Hinze, and Levich applied hydrodynamics approach. VisiMix bridges the gap that separates engineering practice from achievement in the field of mathematical simulation. VisiMix provides chemical and process engineer to perform technical calculations based on the results of the most recent experimental research and mathematical modeling of mixing process [13].

\section{Methods}

\subsection{Data source}

The data used in this paper was obtained from Kuzmanic and Ljubicic [14]. There were $320 \mathrm{~mm}$ of tank diameter, impeller diameter of $106 \mathrm{~mm}$ (the speed of $500 \mathrm{RPM}$ ), ratio liquid height to tank diameter of $1,32.2 \mathrm{~mm}$ of four baffles width, The measurement were conducted using polyethylene particles $\left(\rho=840 \mathrm{~kg} / \mathrm{m}^{3}\right)$ and particles diameter of $200-600 \mu \mathrm{m}, 25.72 \mathrm{~L}$ of water at $15^{\circ} \mathrm{C}$ $\left(\right.$ density $=997 \mathrm{~kg} / \mathrm{m}^{3}$, viscosity $\left.=1,4 \times 10^{-3} \mathrm{~Pa} \mathrm{~s}\right)$. Reynolds number at this speed can be calculated by Equation 3,

$$
R e=\frac{N D^{2} \rho}{\mu}
$$

where $\mathrm{N}$ is impeller speed, $\mathrm{D}$ is impeller diameter, $\rho$ is density, and $\mu$ is viscosity. So the Reynolds number was 66878. The parameter of $\mathrm{N}_{\mathrm{p}}$ can be calculated by Equation 4,

$$
P=N_{p} n^{3} D^{5} \rho
$$

where $\mathrm{P}$ is mixing power, $\rho$ is density, $\mathrm{n}$ is impeller rotation. 


\subsection{Simulation of mixing process}

VisiMix Turbulent SV software was used to simulating mixing tank on lab-scale and industrial scale. The parameters are power per volume $(\mathrm{P} / \mathrm{V})$ and mixing time. $\mathrm{P} / \mathrm{V}$ rule for geometrically similar tank can be used when the density difference between solid and liquid is small [10]. Besides that, the similarity in solid-liquid mass transfer coefficient can be achieved as power per unit volume parameter is maintained. Design of industrialscale tank will be adjusted by changing speed and diameter of impeller and diameter of tank. Propeller impeller used in this simulation, to compare hydrodynamic characteristic. The ratio of $\mathrm{D} / \mathrm{T}$ was $1 / 3$. The data of physical property of liquid obtained to the research [14].

\section{Results and discussions}

In this simulation, we use the results of Kuzmanic Ljubicic [14] as key process parameters with the results shown in Figure 2 and Figure 3.

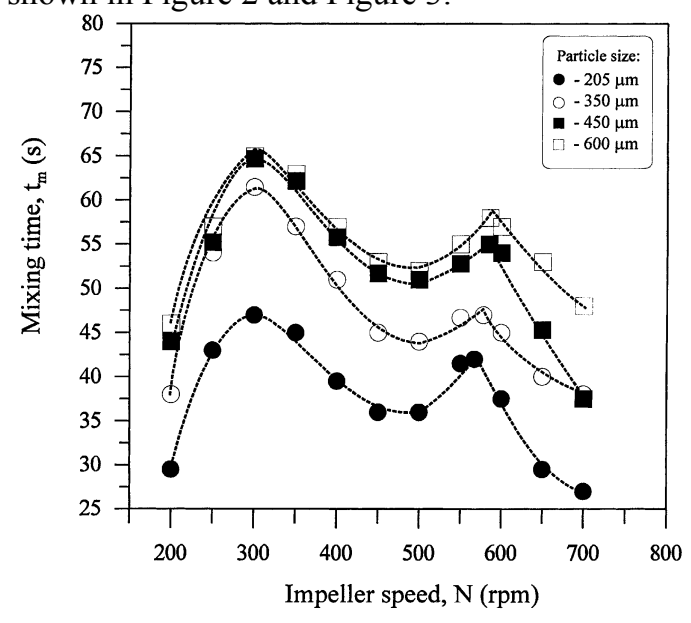

Figure 2. Effect of particle size on the mixing time [14].

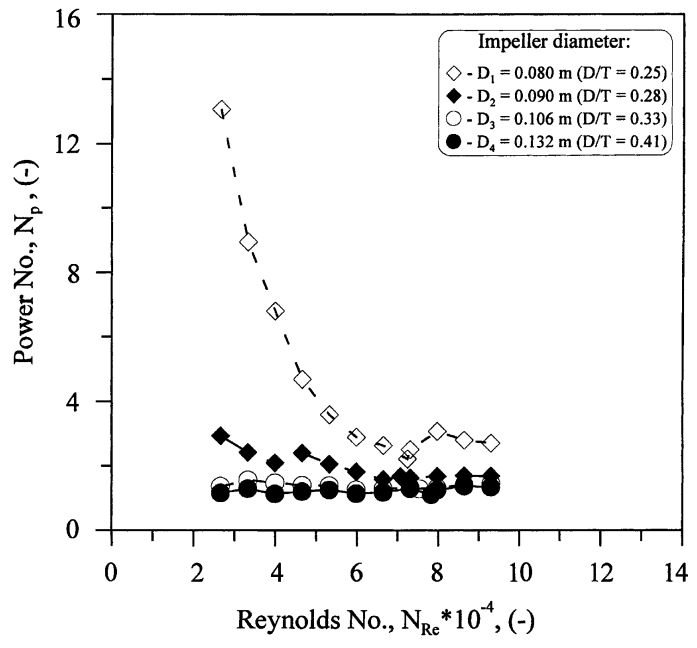

Figure 3. Effect of Reynolds number power number for the different impeller diameter [14].
According to Figure 2 the mixing time value was $36 \mathrm{~s}$. Figure 3 shows the power number was 1.5 so the mixing power was $11.44 \mathrm{~W}$.

\subsection{Scale-up geometry similarity}

The geometry of industrial-scale in this study was $6000 \mathrm{~L}$. According to Figure 1, the tank dimensions are listed in Table 1 .

Table 1. Geometry similarity between lab scale and industrial scale.

\begin{tabular}{ccc}
\hline Geometry & Lab Scale & Industrial Scale \\
\hline Tank diameter & $0.32 \mathrm{~m}$ & $2 \mathrm{~m}$ \\
Impeller diameter & $0.106 \mathrm{~m}$ & $0.668 \mathrm{~m}$ \\
Impeller clearance & $0.106 \mathrm{~m}$ & $0.668 \mathrm{~m}$ \\
Height of liquid & $0.32 \mathrm{~m}$ & $2 \mathrm{~m}$ \\
Baffle width & $0.032 \mathrm{~m}$ & $0.2 \mathrm{~m}$ \\
\hline
\end{tabular}

\subsection{Simulation of $P / V$ parameter}

The power required in mixing process is the key factor to design and operate an impeller. Also, this factor can help an engineer to estimate mixing performance. Therefore, it must be considered that the power in lab-scale and industrial-scale remain similar according to each volume.

Unit volume for mixing tank must be known before determined the ratio of power per volume with Equation 5.

$$
V=\frac{\Pi T^{3}}{4}
$$

According to Equation 5, the volume of lab-scale tank was $0.0257 \mathrm{~m}^{3}$. So the $\mathrm{P} / \mathrm{V}$ value was 445 . The value will be a parameter in this simulation.

The impeller speed will be specify when $\mathrm{P} / \mathrm{V}$ value are as close as possible both two scale. Thus, the speed of impeller rotation was 242 RPM. The simulation results can be seen in Table 2 .

Table 2. Simulation result based on $\mathrm{P} / \mathrm{V}$.

\begin{tabular}{ccc}
\hline Output Calculation & Units & Value \\
\hline Mixing Power & $\mathrm{W}$ & 2820 \\
Torque & $\mathrm{N}^{*} \mathrm{~m}$ & 111 \\
Force applied to impeller blade & $\mathrm{N}$ & 111 \\
Force applied to baffle & $\mathrm{N}$ & 23.9 \\
Impeller tip velocity & $\mathrm{m} / \mathrm{s}$ & 8.53 \\
Macromixing time & $\mathrm{s}$ & 27.5 \\
Depth of Vortex & $\mathrm{M}$ & 0.103 \\
\hline
\end{tabular}

Using Equation 5, the unit volume in industrial scale is $6.33 \mathrm{~m}^{3}$. The power in this simulation was 2820 watt. So the $\mathrm{P} / \mathrm{V}$ value was 445.49 . The value is close to the $\mathrm{P} / \mathrm{V}$ in lab-scale. Therefore, the design of the tank and the impeller on industrial-scale are satisfied.

Sedimentation of solid particles on the tank bottom must be prevented in order to reaches a good quality of liquid-solid mixing. So the impeller speed in this simulation must be higher than Just Suspension Speed (JSS). According to the results of liquid-solid mixing calculation, the pick up conditions is satisfied and the impeller speed is higher than JSS. 
The solid distribution of this simulation are shown in Figure 4 and Figure 5. The corresponding value of axial and radial non-uniformity are 4.54 and 0.189 respectively.

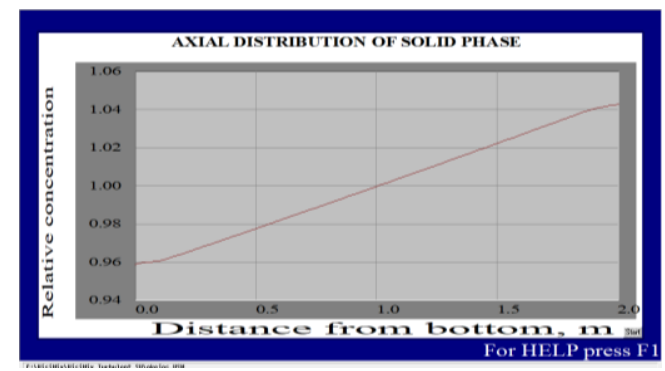

Figure 4. Axial distribution of solid phase in $\mathrm{P} / \mathrm{V}$ parameter.

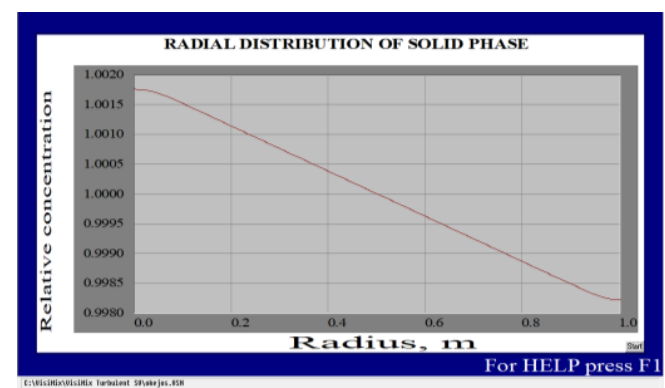

Figure 5. Radial distribution of solid phase in $\mathrm{P} / \mathrm{V}$ parameter.

\subsection{Scale up based on mixing time}

Mixing time is the time required to get a maximum degree of uniformity. It can be predicted by knowing the tank size, impeller design and operating condition, and properties of liquid. Efficiency a mixing process can be known by mixing time. There are two type of mixing time scale, namely micromixing and macromixing [15]. This simulation shows that on 110 RPM of impeller speed, the mixing time was $35.5 \mathrm{~s}$. Table 3, Figures 6 and 7 show the result of the simulation with the same of geometry.

Table 3. Results of simulation based on mixing time.

\begin{tabular}{ccc}
\hline Parameters & Units & Value \\
\hline Mixing Power & $\mathrm{W}$ & 268 \\
Torque & $\mathrm{N}^{*} \mathrm{~m}$ & 23.3 \\
Force applied to impeller blade & $\mathrm{N}$ & 23.2 \\
Force applied to baffle & $\mathrm{N}$ & 6.47 \\
Impeller tip velocity & $\mathrm{m} / \mathrm{s}$ & 3.85 \\
Macromixing time & $\mathrm{S}$ & 35.5 \\
Depth of Vortex & $\mathrm{m}$ & 0.0127 \\
\hline
\end{tabular}

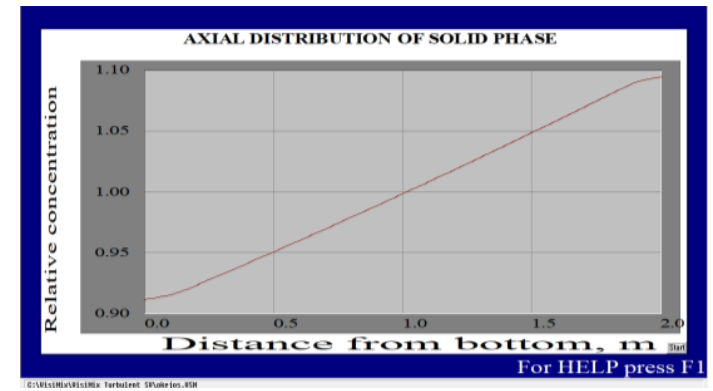

Figure 6. Axial distribution of solid phase in equal blend time parameter.

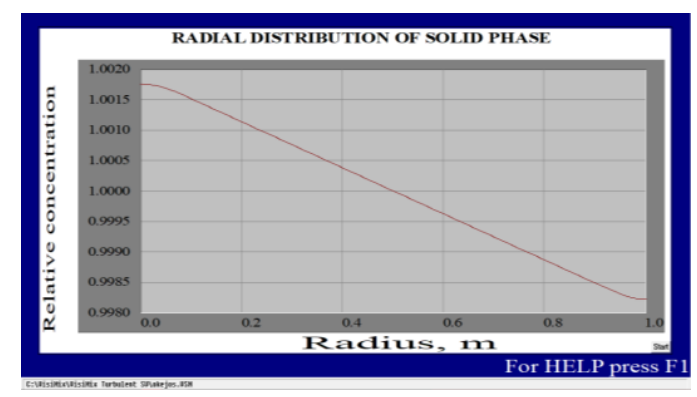

Figure 7. Radial distribution of solid phase in equal blend time.

The corresponding value of axial and radial nonuniformity are 10.1 and 0.189 respectively. Distribution of solid phase in industrial scale based on $\mathrm{P} / \mathrm{V}$ is more uniform than mixing time based parameter.

\subsection{Comparison between $P / V$ and equal blend time}

Table 4 shows the comparison of simulation results between $\mathrm{P} / \mathrm{V}$ and equal blend time.

Table 4. Comparison between $\mathrm{P} / \mathrm{V}$ and equal blend time parameter.

\begin{tabular}{ccc}
\hline Simulation Output & \multicolumn{2}{c}{ Parameters } \\
\cline { 2 - 3 } & $\mathrm{P} / \mathrm{V}$ & Equal Blend Time \\
\hline Torque $\left(\mathrm{N}^{*} \mathrm{~m}\right)$ & 111 & 23.3 \\
Mixing Power $(\mathrm{W})$ & 2840 & 268 \\
Macromixing Time (s) & 27.5 & 35.5 \\
Axial nonuniformity (\%) & 4.54 & 10.1 \\
Radial nonuniformity $(\%)$ & 0.189 & 0.189 \\
\hline
\end{tabular}

From Table 4, it can be seen that the axial distribution of solid phase in $\mathrm{P} / \mathrm{V}$ parameter is more uniform and faster for complete suspension. But, $\mathrm{P} / \mathrm{V}$ parameter gives the higher energy required. Usually equal blend time gives the higher energy than $\mathrm{P} / \mathrm{V}$ parameter because the increasing of impeller speed. It happened because the impeller used in this simulation is different with the research [13]. So in this process, it is better to use propeller rather than pitched blade turbine because with the same of quality of mixing, propeller give a faster process.

\section{Conclusion}

In this paper, power per volume parameter is more recommended as a result of axial non-uniformity (4.54) lower than mixing time parameter (10.1). When the mixing power and cost becomes a consideration, scale-up using mixing time parameter must be chosen due to the power needed of $268 \mathrm{~W}$, much lower than the $\mathrm{P} / \mathrm{V}$ parameter $(2840 \mathrm{~W})$.

\section{Acknowledgment}

The authors are indebted to Ministry of Research, Technology and Higher Education of the Republic of Indonesia for financial support via RAPID grant 2018. 


\section{References}

1. F. Strek, Mixing and stirring apparatuses (Mixer), (WNT, Warsawa,1981)

2. C. Kuncewicz, K. Szulc, and T. Kurasinski, Chem. Eng. Process. 44, 766-774 (2005)

3. A.T. Mak, Thesis, University of London (1992)

4. M. Spidla, M. Mostek, V. Sinevic V, M. Jahoda, V. Machon, Chem. Pap. 59,386-393 (2005)

5. S.M Walas, Chemical Process Equipment Selection and Design (Department of Chemical and Petroleum Engineering, University of Kansas, 1990)

6. R.K. Geisler, C. Buurman, A.B. Mersmann, Chem. Eng. J. 51 29-39 (1993)

7. C. Buurman, G. Resoort, A. Plaschkes, Chem. Eng. Sci. 41,2865-2871 (1986)

8. J.O. Hinze, Turbulence, 2nd edn. (McGraw-Hill, New York, 1975)

9. Th. N. Zwietering, Chem. Eng. Sci. 8, 244-253 (1958)
10. R.E. Brodkey and C. H. Harry, Transport phenomena: A unified approach (McGraw Hill International, New York 1998)

11. V. Koganti, F. Carrol, R. Ferraina, R. Falk, Y. Waghmare, M. Berry, Y. Liu, K. Norris, R. Leasure, and J. Gaudio, Pharm. Sci. Technol. 11(4), 15411548 (2010)

12. D.M. Levins, J.R. Glastonburry, Chem. Eng. Sci. 27,537-543 (1972)

13. VisiMix, "Scientific Backgorund", (2018). Available: http://visimix.com/support/scientific-background/. [Accesed: 01-April-2018]

14. N. Kuzmanic, B. Ljubicic, Chem. Eng. J. 84, 325$333(2001)$

15. A.R. Rao, B. Kumar, Chin. J. Chem. Eng. 17(2), 355-358, (2009) 